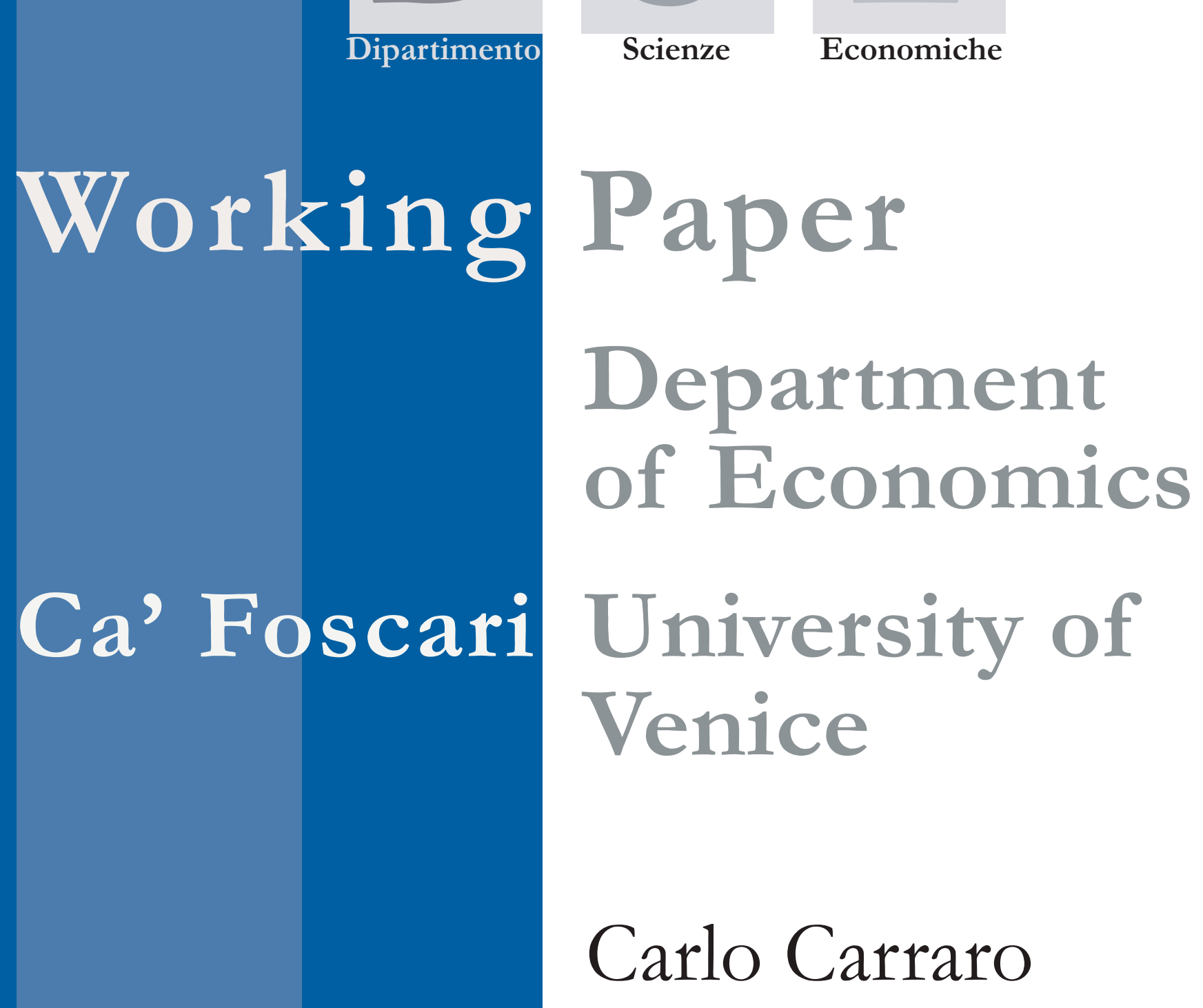




\title{
Incentives and Institutions. A Bottom-up Approach to Climate Policy
}

\author{
Carlo Carraro \\ University of Venice, Fondazione Eni Enrico Mattei, CEPR and CEPS
}

First Draft: June 2006. Revised: September 2006

\begin{abstract}
This paper comments and assesses "Fragmented Carbon Markets and Reluctant Nations: Implications for the Design of Effective Architectures", a paper that David Victor presented at the international workshop on "Architectures for Agreement: Addressing Global Climate Change in the Post-Kyoto World", organized by Joe Aldy and Rob Stavins at the J.F. Kennedy School of Government in May 2006. By analyzing Victor's proposals for an effective climate agreement post 2012, this paper emphasizes the contribution that game-theoretical analyses have provided to the design of climate agreements. It therefore emphasizes how incentives and institutions play a crucial role in affecting the final outcome of negotiations on climate change control, and how incentives and institutions can be modified to achieve a better control of climate change. This paper also discusses a wider policy approach that can enhance the effectiveness of measures designed to address the climate change problem.
\end{abstract}

\section{Keywords}

Agreements, Climate, Incentives, Negotiations, Policy

\section{JEL Codes}

C72, H23, Q25, Q28

Address for correspondence: Carlo Carraro

Department of Economics Ca' Foscari University of Venice Cannaregio 873, Fondamenta S.Giobbe 30121 Venezia - Italy Phone: (++39) 0412349166 Fax: (++39) 0412349176 e-mail:ccarraro@unive.it

This Working Paper is published under the auspices of the Department of Economics of the Ca' Foscari University of Venice. Opinions expressed herein are those of the authors and not those of the Department. The Working Paper series is designed to divulge preliminary or incomplete work, circulated to favour discussion and comments. Citation of this paper should consider its provisional character.

The Working Paper Series is availble only on line (www.dse.unive.it/pubblicazioni) For editorial correspondence, please contact:wp.dse@unive.it
Department of Economics

Ca' Foscari University of Venice

Cannaregio 873, Fondamenta San Giobbe

30121 Venice Italy

Fax: ++390412349210 


\section{Incentives and Institutions. A Bottom-up Approach to Climate Policy*}

1. Incentives and institutions. These are the two cornerstones of David Victor's analysis. Incentives and institutions have often been neglected in the study of climate policy, which mostly focused on concepts like optimality or cost effectiveness. Most economic analyses of climate policies have indeed focused on a global target and on the optimal or cost effective way to achieve it, but they largely neglected the incentives for negotiating countries to agree on the target, disregarded the policy instruments that can provide these incentives, and did not pay adequate attention to the institutions that are necessary to implement the policy instruments and enforce the target.

The paper by David Victor fills this gap. It carefully analyses both incentives and institutions, first in relation to the Kyoto Protocol, then to identify some features of an alternative policy architecture. As for the Kyoto Protocol, Victor emphasizes the weakness of international institutions that should implement the Protocol rules and achieve the Protocol targets. He correctly criticizes the Protocol's objective of achieving universal participation, its focus on binding targets, and the lack of effective measures to get developing countries involved in the cooperative effort to control climate change.

However, the main contribution of David Victor's paper is not his analysis of the Kyoto Protocol. His main lesson is that the design of any future agreement on climate policy must start from analyzing each country's incentives to participate in the agreement, and then move to identify policy instruments and institutions that provide adequate incentives to reluctant countries. ${ }^{\dagger}$

\footnotetext{
"Paper presented at the workshop "Architectures for Agreement: Addressing Global Climate Change in the Post-Kyoto World", J.F. Kennedy School, Harvard University, May 12-13, 2006. The author is grateful to Joe Aldy and Rob Stavins for helpful suggestions and remarks. The usual disclaimer applies. ${ }^{+}$This point is not new - see for example Chapter 11 in IPCC TAR (2001) - but is not yet adequately considered in many policy analyses and in actual policymaking.
} 
He draws this lesson from a careful analysis of recent events in international climate negotiations and domestic policymaking. His main conclusions are not new. Similar results have been achieved in the recent theoretical literature on international environmental agreements (Cf. Carraro and Siniscalco, 1993; Barrett, 1994; See Carraro and Marchiori, 2003 for a survey). However, rather than using a general and sometimes unrealistic game-theoretic framework, Victor develops his arguments by looking at the reality of existing policy institutions and markets. From this viewpoint his analysis his novel, well rooted and more convincing than previous ones. In addition, many features of the new policy architecture that he proposes are also interesting and original.

Nevertheless, to understand the importance and the robustness of David Victor's analysis, let me first summarize the main motivations and results of the game-theoretic literature. This would also help highlighting similarities and differences between theoretical works and David Victor's contribution.

2. Among the transnational policy issues, environmental protection is a limiting case. In areas such as global warming, ozone layer depletion and biodiversity, spillovers, as well as the absence of clear property rights, create strong incentives to free ride which undermine co-operation. Hence, the difficulty of reaching agreements which are both effective and widely accepted.

The above problems are not new to economists, and have been analyzed in the area of externalities and public goods. What is new is the context in which these problems take place. Currently, climate change control is managed as a global common-property good, but there is no institution which possesses powers to regulate it by means of supranational legislation, economic instruments, or by imposing a system of global property rights. Hence, the necessity to design negotiation mechanisms leading to self-enforcing agreements, i.e. agreements to control climate change which are voluntarily signed by a "large" group of countries (large enough to keep climate change under control). 
Economists are quite skeptical about the possibility of achieving self-enforcing agreements on climate change. Early contributions (Cf. Hardin and Baden, 1977) would have characterized the climate control game among countries as a prisoner's dilemma, inevitably leading to the so-called "tragedy" of the common property goods. But in the real world, a large number of international environmental agreements on the commons have been signed, often involving sub groups of negotiating countries and sometimes involving transfers and links to other policies (trade, technological cooperation, etc.). This is why the "prisoner's dilemma” approach is unsatisfactory and new conceptual models have been developed, which proved more helpful in understanding the logic of international cooperation in the presence of positive spillovers. These new models were developed in the last decade within a non-cooperative game-theoretic framework, and provide interesting indications on the likely outcomes of climate negotiations (Cf. Carraro and Marchiori, 2003; Finus and Rundshagen, 2003 for surveys of the literature).

3. The main results of the game-theoretic literature can be summarized as follows.

- The presence of asymmetries across countries and the incentive to free-ride make the existence of global self-enforcing agreements, i.e. agreements which are profitable to all countries and stable, quite unlikely (Carraro and Siniscalco, 1993; Barrett, 1994).

- When self-enforcing international environmental agreements exist, they are signed by a limited number of countries (Hoel, 1992, 1994; Barrett, 1994).

- When the number of signatories is large, the difference between the cooperative behavior adopted by the group of signatories and the non co-operative one is very small (Barrett, 1997).

- The grand coalition, in which all countries sign the same environmental agreement, is unlikely to be an equilibrium (Finus and Rundshagen, 2003). 
- The equilibrium coalition structure is not formed by a single coalition (a single group of signatories). In general, more than one coalition forms at the equilibrium (Bloch, 1997; Yi, 1997).

- Coalitions of different sizes may emerge at the equilibrium, even when countries are symmetric (Ray and Vohra, 1997; Carraro and Marchiori, 2003; Yi, 1997). ${ }^{\ddagger}$

The lesson that can be drawn from these results can be phrased as follows. A global agreement is unlikely to be signed by all the relevant countries. Several parallel agreements are going to emerge over time. Domestic measures and/or policies implemented by small groups of countries are going to be adopted to control climate change.

These predictions are consistent with David Victor's ones. For example, he writes: “The integrated international market for emissions ... has not yet materialized; instead at least six different carbon markets have emerged", and "Too much attention has focused on global institutions and not enough on the more diverse national and regional bodies”. For the future, he sees: “An extensive use of nonbinding agreements among smaller groups of countries and allowance for fragmented emission trading systems”. And also: “The future landscape will be dominated by multiple (permit) prices”.

Similarly to Victor, several authors working within a game-theoretic framework have used their results to question the design of the Kyoto Protocol (Cf. Carraro, 1998; Bloch, 2003; Finus and Rundshagen, 2003; Yi, 2003; Bretteville et al., 2004; Buchner and Carraro, 2006). They argue that the Kyoto Protocol is unlikely to be signed by all relevant players and that the emergence of alternative, parallel climate blocs is likely. Some indications that multiple regional or sub-global climate blocs could be the

\footnotetext{
₹ The specific results on the size of the coalitions depend on the model structure and in particular on the slope of countries' reaction functions, i.e. on the presence of leakage. If there is no leakage and countries are symmetric, then the Nash equilibrium of the multi-coalition game is characterized by many small coalitions, each one satisfying the properties of internal and external stability (Cf. Carraro and Marchiori, 2003).
} 
appropriate way to address the difficulties emerging in climate negotiations can also be found in the political science literature (see for example, Egenhofer and Legge, 2001; Egenhofer, Hager and Legge, 2001; Stewart and Wiener, 2003; Reinstein, 2004; Carraro and Egenhofer, 2006).

The basic idea in all these contributions is that a bottom-up, country-driven approach to defining national commitments should be adopted. Instead of top-down, global negotiations on national emission targets, each country or group of countries would determine its contribution to a cooperative effort to curb GHGs and choose the partners with whom it intends to cooperate. In a process analogous to trade negotiations, each country would put its offer of commitments on the negotiating table and invite proposals from other countries for similar commitments.

4. A fragmented climate regime characterized by the formation of climate blocs (regional coalitions for example) would then emerge in much the same way as is now emerging in trade negotiations. This should not be surprising. As Victors correctly says, in substance, even though not in form, the Kyoto Protocol already reflects agreements among several different coalitions. It incorporates special provisions for several different groups of countries. The Non-Annex B countries have no commitments and can benefit from emission reduction investments through the CDM. The most vulnerable Non-Annex B countries can also receive financial assistance for adaptation from the levy imposed on the CDM (and possibly on the other mechanisms). The European Union has the ability under Article 4 to redistribute the emissions reduction burden. Australia ha obtained/negotiated a special provision on land use emissions in Article 3.7.

\footnotetext{
$\S$ As has been stressed by Egenhofer and Legge (2001), "it is increasingly becoming clear, [that] the Kyoto Protocol is less a global agreement than a set of differing regional approaches”.
} 
In addition, the lesson that can be derived from trade negotiations consistently tells us that progress on trade liberalization can be achieved mostly through regional agreements, at least in the coming years. ${ }^{* *}$ In international trade, the "resurgence” of regionalism has thus become a crucial subject, underscored by the formation of competing customs unions and the debate about free trade areas. Substantial attention has been focused on the efficiency and implications of these regional or sub-global cooperations (Cf. Baldwin, 1993; Casella, 1995; Bloch and Ferrer, 1999; Bond and Syropoulos, 1996; Krugman, 1991; Yi, 1996a, 1996b and 1998).

In particular, several authors have pointed out that Regional Trade Agreements (RTAs) may seem to be contradictory, but they can often actually support the WTO's multilateral trading system (Cf. Sampson and Woolcock, 2003). Regional agreements have allowed groups of countries to negotiate rules and commitments that go beyond what was previously possible multilaterally. In turn, some of these rules have paved the way for agreements within the WTO. Services, intellectual property, environmental standards, investment and competition policies are all issues that were raised in regional negotiations and later developed into agreements or topics of discussion in the WTO. ${ }^{\dagger \dagger}$ For these reasons, on 6 February 1996, the WTO General Council created the Regional Trade Agreements Committee. Its purpose is to examine regional groups and to assess

\footnotetext{
** The strong increase in the number of trade bloc agreements registered with the World Trade Organisation is discussed in Tjornhom (2000) and Boonekamp (2003). Some 250 regional trade agreements (RTAs) have been notified to the GATT/WTO up to December 2002, of which 130 were notified after January 1995. About 200 RTAs are currently in force. An additional 70 to 100 are estimated to be operational although not yet notified. RTAs, which includes bilateral free trade agreements between countries that are not in the same region, have become so widespread that all but one WTO member are now parties to one or more of them. Indeed, as of August 2006, all 146 WTO Members, with the exception of Mongolia, participate in or are actively negotiating regional trade agreements.

${ }^{\text {It }}$ The groupings that are important for the WTO are those that abolish or reduce barriers to trade within the group. The WTO agreements recognize that regional arrangements and closer economic integration can benefit countries. It also recognizes that under some circumstances regional trading arrangements could hurt the trade interests of other countries. Normally, setting up a customs union or free trade area would violate the WTO's principle of equal treatment for all trading partners ("most-favoured-nation"). But GATT's Article 24 allows regional trading arrangements to be set up as a special exception, provided certain strict criteria are met. In particular, the arrangements should help trade flow more freely among the countries in the group without barriers being raised on trade with the outside world. In other words, regional integration should complement the multilateral trading system and not threaten it.
} 
whether they are consistent with WTO rules. The committee is also examining how regional arrangements might affect the multilateral trading system, and what the relationship between regional and multilateral arrangements might be.

A similar process may be envisaged for the case of climate change control. Some domestic or regional initiatives to reduce GHG emissions today may pave the way to a global agreement tomorrow.

The parallelism with trade negotiations is used also by David Victor to claim that a new policy architecture, no longer based on binding agreements and on a global target, would be more effective in reducing global GHG emissions.

\section{The basic ingredients of the policy architecture would be:}

- The coordination of a variety of efforts. Countries would agree on things to do rather than on emission reduction targets.

- A variable geometry of participation. Some countries would agree on more efforts than others.

- A sufficient accountability system to ensure that commitments become connected to action.

How can this be achieved? David Victor does not neglect the negotiation process and the related institutions. He emphasizes how more and better cooperation on GHG emission control could be achieved by limiting the number of negotiating countries to the most important ones (e.g. the 20 top polluters). He also highlights the importance of issue linkage and transfers (through economic cooperation). And the necessity of a mechanism for review and scrutiny. 
Again all this is not completely new. There is, for example, a large literature on both issue linkage and transfers (among many others, two recent contributions are Buchner et al., 2005, and Carraro, Eyckmans and Finus, 2006) that highlights under what conditions these mechanisms can enhance participation incentives and lead more countries to agree on GHG emission abatement.

What is new in David Victor's paper is the careful analysis of what these mechanism could be in practice. For example, how can scrutiny be designed or where economic cooperation can effectively reduce GHG emissions (e.g. by building natural gas infrastructures in China). What David Victor does is to give substance and realism to ideas and results that were developed via mathematical models and therefore were unable to deal with the details of the actual policy process. We have seen that the theoretical economic literature supports David Victor's analysis. But the other way around is also true. David Victor's gives meaning and appeal to the theoretical results.

It is also important to stress the relevance that Victor gives to the role of institutions. A bottom up approach is to be favored not only because the underlying participation incentives inevitably leads to a fragmented climate policy regime, but also because the institutions which are capable to implement an effective climate policy do not yet exist at the international level, but sometimes exist at the domestic and regional level. Therefore, a club approach, in which cooperation takes place on specific dimensions where (a few) participating countries have institutions that guarantee compliance and effectiveness, becomes the appropriate one.

6. Three elements of David Victor's proposal deserve additional scrutiny. It is clear that in terms of incentives and institutions a bottom-up approach is the only one with chances to succeed in curbing GHG emissions. A set of coordinated efforts with a variable participation geometry is likely to be the future of climate policy. However, by relying only on self-interests, this approach may not succeed in achieving the large 
emission reductions that most scientists believe to be necessary to control climate change. Is there a way of assessing the amount of emission reduction that a bottom up approach is likely to achieve in the next fifty years?

A second elements concerns equity and burden sharing. If countries agree on different sets of efforts, how can the costs of these efforts be assessed and compared? For example, is there a way to claim that the effort to develop new energy technologies (e.g. in the US) is larger or costs more than the effort to replace coal power plants (e.g. in Germany or China) or the effort to accept higher temperatures at home and at work in the summer (as recently suggested by the Japanese Minister of the Environment)? Is there a metric of efforts?

Finally, David Victor's policy architecture does not mention adaptation. Adaptation, whatever we do to reduce GHG emissions and whatever the anthropic influence on climate change, will be needed. The related large investments are likely to crowd out other investments, including those to reduce emissions. Is there a link between mitigation and adaptation in David Victor's proposal? Can the set of coordinated efforts proposed by Victor also include the effort to adapt to climate change? Given the policymakers' discount rate, the costs of adaptation (to be paid far in the future) is likely to be smaller than the costs of mitigation (to be paid in the coming years), unless some catastrophic impacts of climate change are expected. Does this mean that a coordination of efforts to adapt our economic systems and lifestyles to climate change will crowd out most efforts to reduce GHG emissions?

These three questions are relevant for all policy architectures and not only for the one proposed by Victor. The answer to these questions is a necessary complement to all policy proposals on GHG mitigation. And the three questions are strictly interlinked. For example, if countries' incentives and institutions lead to a set of regional or sub global agreements that are unable to provide a sufficient amount of emission abatement, than more adaptation efforts would be necessary. Are there incentives and institutions to 
provide the right amount of adaptation investments? As another example, it is well known that some countries are more vulnerable than others to climate change. How can the costs of adapting to climate change be distributed in a fair and acceptable way among world countries? Is an adaptation fund the appropriate answer to this question? How should contributions to the adaptation fund be designed?

7. Conclusions. Let me conclude by summarising my own version of David Victor's policy architecture (which is also my own favoured policy architecture). Let me start from the number of negotiating countries: as recently proposed by the Canadian Prime Minister, twenty is probably the right number, but a slightly smaller number would also be appropriate. Then, the issues on which these countries will negotiate have to be defined. Technological cooperation, climate relate trade rules, carbon taxation, carbon sinks, contribution to a global adaptation fund, forestry preservation, biofuels, development aid, energy infrastructures, are some examples. For each issue a number of countries, not necessarily the same countries, not necessarily the same number, decide to cooperate. This decision implies both that some measures are adopted in each country (or small group of countries) to achieve a common issue-specific objective, and that a system of monitoring and enforcement is established amongst the signatory countries. A regular verification process of how different measures are implemented in each country or group of countries (and of their impacts and costs) can also be agreed upon. Regular meetings can be organised to update the set of countries cooperating on each issue. Whenever the verification process identifies an insufficient effectiveness of the adopted measures or an unequal sharing of the burden of controlling climate change, new measures or a new distribution of existing measures have to be negotiated. Given that all measures are implemented domestically or within a bilateral or regional cooperative setting (e.g. the European Union or Mercosur), the establishment of new global or supra-national institutions would not be necessary. 
This framework implies that climate change is no longer an environmental problem to be dealt with specific environmental policy measures. It is a global economic problem to be dealt with global economic policy measures. Whatever the issue that world leaders are going to analyse and discuss, climate change should be a dimension of their own analysis and discussion.

\section{References}

Baldwin, R. (1993), A Domino Theory of Regionalism. NBER Working Paper No. 4465.

Barrett, S. (1994), Self-Enforcing International Environmental Agreements, Oxford Economic Papers, 46, 878-894.

Barrett, S. (1997), Towards a Theory of International Co-operation in C. Carraro and D. Siniscalco, eds., New Directions in the Economic Theory of the Environment, Cambridge University Press, Cambridge.

Bloch, F. (1997), Non-co-operative Models of Coalition Formation in Games with Spillovers, in C. Carraro and D. Siniscalco, eds., New Directions in the Economic Theory of the Environment, Cambridge University Press, Cambridge.

Bloch, F. and H. Ferrer (1999), Trade Fragmentation and Coordination in Bilateral Oligopolies. CORE Discussion Paper No. 9908.

Bond E. and C. Syropoulos (1996), The Size of Trading Blocs. Market Power and World Welfare Effects. Journal of International Economics, Vol. 40 (1996), 417-37.

Boonekamp, C. (2003), The Changing Landscape of RTAs, WTO Secretariat, Trade Policies Review Division, prepared for the Seminar on "Regional Trade Agreements and the WTO”, WTO Secretariat, Geneva, 14 November 2003.

Bretteville, C., Hovi, J. and F.C. Menz (2004), Regional versus Global Cooperation for Climate Control, mimeo, Cicero, Oslo, Norway.

Buchner, B. and C. Carraro (2006), Parallel Climate Blocs. Incentives to Cooperation in International Climate Negotiations, forthcoming in R. Guesnerie and H. Tulkens, (eds.), The Design of Climate Policy, MIT Press, Cambridge.

Buchner, B., C. Carraro, I. Cersosimo and C. Marchiori (2005), Back to Kyoto? US Participation and the Linkage between R\&D and Climate Cooperation. In A. Haurie and L. Viguier, eds., Coupling Climate and Economic Dynamics, Kluwer Academic Publishers, Dordrecht. 
Carraro C. (1998), Beyond Kyoto : A Game-Theoretic Perspective, paper presented at the: OECD Experts Workshop on Climate Change and Economic Modelling: Background Analysis for the Kyoto Protocol, Paris, September 17-18, 1998.

Carraro, C. (2004), Institution Design for Managing Global Commons, in G. Demange, D. Ray and M. Wooders, eds., Group Formation in Economics. Networks, Clubs and Coalitions, Cambridge University Press, Cambridge.

Carraro, C. and D. Siniscalco (1993), Strategies for the International Protection of the Environment, Journal of Public Economics, 52, 309-328.

Carraro, C. and C. Egenhofer, eds., (2006), Climate and Trade Policy. Bottom-up Approaches towards Global Agreement, E.Elgar, Cheltenham. Forthcoming.

Carraro, C., Eyckmans, J. and M. Finus (2006), Optimal Transfers and Participation Decisions in International Environmental Agreements, forthcoming in the Review of International Organizations.

Carraro, C. and C. Marchiori (2003), Stable Coalitions, in C. Carraro, ed., The Endogenous Formation of Economic Coalitions, E.Elgar, Cheltenham.

Carraro, C. and D. Siniscalco (1998), International Environmental Agreements: Incentives and Political Economy, European Economic Review 42, 561-572.

Casella, A. (1995), Large Countries, Small Countries and the Enlargement of Trade Blocs. NBER Working Paper No. 5365.

Demange, G., Ray, D., and M. Wooders, eds. (2005), Group Formation in Economics. Networks, Clubs and Coalitions, Cambridge University Press, Cambridge.

Egenhofer, C. and T. Legge (2001), After Marrakech: The Regionalisation of the Kyoto Protocol. CEPS Commentary.

Egenhofer, C., W. Hager and T. Legge (2001), Defining Europe's Near Abroad in Climate Change: A Russian-EU Alliance - Sub-global Bargaining to Further International Environmental Agreements. CEPS Discussion Paper.

Krugman, O. (1991), Is Bilaterism Bad? In E. Helpman and A Razin (eds.), International Trade and Trade Policy. MIT Press: Cambridge.

Heal, G. (1994), The Formation of Environmental Coalitions, in Carraro, C., ed., Trade, Innovation, Environment, Kluwer Academic Publisher, Dordrecht.

Hoel, M. (1992), International Environmental Conventions: the Case of Uniform Reductions of Emissions, Environmental and Resource Economics, 2, 141-159.

Hoel, M. (1994), Efficient Climate Policy in the Presence of Free-Riders, Journal of Environmental Economics and Management, 27, 259-274.

IPCC (2001), Third Assessment Report, Volume 3, Chapter 10, Section 2, Cambridge, Cambridge University Press, 2001.

Ray, D. and R. Vohra (1997), Equilibrium Binding Agreements, Journal of Economic Theory, 73, 30-78.

Ray, D. and R. Vohra (1999), A Theory of Endogenous Coalition Structures, Games and Economic Behavior, 26, 286-336. 
Reinstein, R. A. (2004), A Possible Way Forward on Climate Change, mimeo, Reinstein \& Associates Inc.

Sampson, G. and S. Woolcock (2003), Regionalism, Multilateralism, and Economic Integration. The Recent Experience, Tokyo, the United Nations University Press.

Stewart, R and J. Wiener (2003), Reconstructing Climate Policy, American Enterprise Institute Press.

Taylor, M. (1987), The Possibility of Cooperation, Cambridge University Press, Cambridge.

Tjornhom J. (2000), Dynamic Trade Bloc Formation: Building Blocs or Stumbling Blocs? University of Minnesota

Yi, S.-S. (1996a), Endogenous Formation of Customs Unions under Imperfect Competition: Open Regionalism is Good. Journal of International Economics, Vol. 41 (1996), 153177.

Yi, S.-S. (1996b), Open Regionalism and World Welfare. Eastern Economic Journal, Vol. 22, No. 4, Fall 1996, 467-475.

Yi, S.-S. (1997), Stable Coalition Structures with Externalities, Games and Economic Behaviour, 20, 201-23.

Yi, S.-S. (1998), Free trade Areas and Welfare: An Equilibrium Analysis. Dartmouth College, Department of Economics. 